\title{
Conflict Management Styles of Female Androgynous Supervisor and Subordinate
}

\author{
Nehal B. Solanki ${ }^{1}$
}

\begin{abstract}
:
The recent trends and challenges have brought dramatic changes in terms of creating virtual workplaces for both men and women. The present study aims to investigate feminine androgynous supervisors and subordinates who belong to rural and urban area and their differences in conflict management styles in work setting, research was conducted on the differences between status, residential area and preferred conflict management strategies. Identify the differences between androgynous female supervisor and subordinates and their adopted to resolve interpersonal conflict. The sample consisted of 220 Organizational androgynous female employees selected randomly from various branches of Rajkot districts. The Bem's Sex Role Orientation (BSRO) inventory adapted in Indian setting by Rao, Gupta and Murthy was used to measure gender role. Rahim's Organization Conflict Inventory (ROCI-II) was used to measure Conflict management style. The study reflects that significant effect between supervisor and subordinates conflict management styles and there was significant interactional effect of status and residential area.
\end{abstract}

Keywords: Organizational status, Residential area, Conflict management styles.

Conflict is presumed to be present in almost every context of human interaction, which makes the importance of conflict management strategies highly significant. Conflict management strategies vitally increase the performance and effectiveness of an individual and in turn the effectiveness of the organization as a whole. Within this scenario, the main focus is on the human being itself and the manner in which each individual manages conflict.

Significant attention has been received by the group conflict management within the organizations in the academic and nonacademic literature. (Wall \& Callister, 1995; Jehn, 1997; Jameson, 1999; Rahim, 2000, 2001, 2002; Pearson, Ensley \& Amson, 2002; De Dru \& Weingart, 2003). Not only research but also the practitioner's interest in conflict management reflects the fact that conflict is inevitable in organizational and social life (Cosier \& Ruble, 1981; Miles, 1980), and researches show that managers spend a major amount of their time dealing with conflict (Pondy, 1992; Pulhamus, 1991; Thomas \& Schmidt, 1976).

\footnotetext{
${ }^{1}$ Department of Psychology, Saurashtra University, Rajkot, Gujarat
} 
Conflict: There are myriad possibilities to define conflict probably as many as there are occasions for it to happen One set of definitions recommends so as; conflicts present in situations where there are apparent differences in interests, views, or goals. Another such that of Deutsch (1973) implies that for a conflict to be present, one party must in fact obstruct the ambitions of another. Yet again there are definitions resembling Abel (1982) which uphold the view of incompatible assertion to assets. Felstiner, Abel and Sarat (1981) and Mather and Yngvesson (1980-1981) rightly suggest that the explanation of conflict diverges because of the different perceptual and behavioral interpretations of various parties; therefore any definition must be flexible in order to fit in the context. The deficiency in much of the literature is the distinction between the actual conflict and its cueing circumstances. Pondy (1967) advocates that literature over the time presents conflict as being referred to as either of the following:(a)the Precursor conditions of conflict full behavior such as scarcity of resources, policy differences etc., (b) the Affective level of the individuals in the conflict such as strain, worry, resentment, fear, etc (c) the Cognitive level of those involved in the conflict such as their perceptions about and awareness of the conflict full situations (d) the actual conflict full behavior of the individuals involved in the conflict; this behavior continuum initiates from submissive resistance and ends on open hostility Conflict has two approaches; to begin with the one which follows Schmidt and Kochan (1972), which focuses upon incidents pertinent to competitive intentions, comparable as purposely interfering with the differing individual's or party's goals, interests or views. This characterization is nearer to accepted practice of the expression conflict in the industrial relations literature (e.g. strikes and job actions). The next approach which follows Pondy (1967) and the 1976 Handbook chapter, envelops those events (usually perceptions) which precede the selection of conflict-management styles. To formulate a more clear and comprehendible picture and a more workable definition which surrounds different aspects of conflict, based on the contemporary literature, Conflict are the real or perceived perceptions, emotions and behaviors of the individuals or parties as well as the contexts and backgrounds in which the conflict takes place, which could be before (the taking into account the antecedent conditions) the conflict or synchronized with it, taking place at the actual moment of conflict.

Conflict management styles: Rahim and Bonama's (1979) categorization of the styles of settling interpersonal conflict is based on two facades, first when a person considers himself and his own concerns and the second when a person considers others and the concerns of others. Each of the dimensions is a continuum in nature, therefore consideration of the interests of one's own self or of the others', can be high or low. Moreover based on these two dimensions a third dimension can be analyzed which is a state in the middle where a person possesses a bit of both the facades that is to say consideration of one's own interests as well as the other's. Taking these categories as the foundation, five particular conflict managing styles have been devised namely (a) Integrating, in which a person highly considers his own interests as well as the interests of the other's, (b) Avoiding, is just the opposite of the integrating style, it is when a person has neither a concern for himself nor the others indicating low concerns in both the major two dimensions, (c) Obliging is a state in which a person does possess a high concern for others but possesses a low concern for himself. (d) Dominating, is the reciprocal of the obliging style of conflict 
management, it is when a person has a high concern for own interests but a low concern for the interests of the other's. Last but not the least (e) Compromising style is the category which comes under the third dimension, this is when a person has some consideration for himself and some for the other.

Integrating: From the theoretical aspect on integrating style, it is presumed to produce a lesser conflict loaded atmosphere; Fisher and Ury (1991) support the argument of integrating in such a manner that a well judged, effective and efficient outcome of any dispute would only be by the means of careful and effortful examination of the aims and well being of all the persons involved. Experimental research indicates resembling opinions, of the sort of Pruitt et al, it shows that the peak level of mutual rewards were accomplished when negotiators possessed both a high concern for self and a high concern for others.

Obliging: Obliging refers to a more concern for others rather than for one's self, it also refers to easily giving up own interests for the sake of fulfilling other's. This strategy apparently seems an unproblematic way to patch up disagreements but not an always entirely efficient option. In obliging style one faction plainly gives in to the aims and interests of the other faction, in anticipation of resolving the conflict. A study by Fry, Firestone, and Williams (1983) concluded that members who are reluctant to stand up for their own requirements and which only looked after their partner's interests and needs of newly formed couples, , inclined to admit so quickly that they fail to spot the opportunities for collective benefits.

Dominating: When persons consider their own interest more than that of the others that is when they use the 'Dominating' style. People who use this style hold the view that by addressing at least their side of the disagreement and their own needs, will partially resolve the conflict. The possibility also remains that using such conflict handling style in which only one side of the problem is addressed will not conclude to complete and effective solution to the problem. According to Pruitt et al, dominating style users overlooked joint achievements.

Avoiding: People those who use an avoiding style of conflict management are deficit of the awareness of the problem's importance or how to deal with it. Not only do they lack consideration for themselves because they feel awkward to signify themselves, but also a low consideration for others as well which makes it difficult for them to understand other persons problems, need and interests. The avoiding style users are quite unable to devise better and effective solutions or alternatives to their conflict problem because they don't possess the fundamental knowledge of their own concerns or the other's besides not being much aware of the problem itself. With such contexts where there are lesser resources to employ ultimately tend to lesser probability of resolving the conflict, thereby unnecessarily stretching the problem. Hence people who avoid the problem are expected to encounter many and usually longer problems.

Compromising: Compromising is a pivotal sort of style more like barter where one has to give something to get something likewise here both the factions have to give up some of their own concerns in order to achieve an equilibrium position of agreement. This takes place when there is equal consideration for one's own concerns and the concerns of others. It would be win-win strategy in most cases from the fact that all the persons compromising end up satisfied because 
neither of the factions entirely loses, but not to forget that neither of the factions entirely wins; only partial. Compromising is achieved by better communication of all the concerns among the persons involved and through mutual recognition of the requisites. Compromising would lead to the attainment of a different objective than that of the original.

This study will conceptualize conflict management strategies as the preferred choice of handling a conflict dependent on the parties involved in the conflict. A definition that considers possible variance in conflict management styles was chosen because conflicts are often times managed differently according to the parties involved and the context surrounding the conflict.

We also note that there has been little direct evidence that bears directly upon gender differences at higher management levels. The Chusmir and Mills (1989) study, which included men and women managers at three levels, found no significant gender effect after controlling for organization level. However, their data show some conversation between gender and organization level which could explain that finding. Some studies have found smaller gender differences among managers than non-managers (Korabik et al., 1993) or have found smaller differences among more experienced managers (Sorenson et al., 1995), suggesting that male and female conflict styles may converge at higher levels.

As previously stated, the focus of this study will be on the relationship between gender and conflict management styles in an organizational setting. There is little previous research that has incorporated a multidimensional treatment of conflict management strategies, and further research is necessary (Canary, Cunningham, \& Cody, 1988; Song, et al., 2006). When looking at differences in conflict management styles in a workplace, an organizational variable such as status may help to explain the possible variance in conflict management styles. Status can be ambiguous; however, for the purpose of this study, status will be defined as "the organizational position that is occupied relative to others in the workplace" (Domagalski \& Steelman, 2007). Multiple studies have addressed that status is a crucial aspect of organizational conflict management. Putnam and Poole (1987) explain that status has been underemphasized in most organizational communication research, and when researching conflict management styles the "choice of style may...hinge on the organizational position of the opponent in a conflict". Additionally, Gross and Guerrero (2000) explored the appropriate and effective management of conflict, and suggested that the organizational positions of co-worker, superiors, and subordinates may have an impact on conflict management styles. A previous study used three similar financial organizations and looked at gender roles, conflict management strategies, and status in workplaces (Brewer et al., 2002). Additionally, the previous study explored conflicts with peers and not conflict between members of a different status (Brewer et al., 2002). There has been a great deal of research conducted on the communication between superiors and subordinates, which has demonstrated that the relationship between subordinates and superiors is unique (Infante \& Gorden, 1981; Lamude, Daniels, \& Grahm, 1988). When communicating with superiors, subordinates will often say what they feel to be acceptable but not necessarily true (Rahim, 1983). The differences in communication between superiors and subordinates may have an impact on the conflict management strategies used in a conflict between superiors and 
subordinates. As a result, this current study will explore status and conflict management between members of different organizational positions in a workplace in order to develop a more in-depth understanding of conflict management.

\section{OBJECTIVES:}

The objective of present study was as mentioned below:

- To study the impact of Androgynous Female Employees Status (SupervisorSubordinates) on conflict management styles of organizational employees.

- To study the impact of Residential area (Rural and Urban) on conflict management styles of organizational employees.

\section{METHOD}

\section{Participants:}

The sample consisted of 220 Androgynous female employees working as supervisor and subordinates who lives in rural and urban area, Who are working in post office, telecom office and bank sector were selected to collect required information. These all institutions were selected from Rajkot city.

\section{Instruments:}

For data collection following tool were used:

Conflict Management Style inventory: Preferred conflict management styles were measured through the Rahim Organizational Conflict Inventory II (ROCI-II) (Rahim, 1983). The participants were asked to respond on a 5-point Likert scale to each of the 28 items. The ROCI-II measures each participant's preferred conflict management style by classifying it into one of the five conflict resolution approaches: integrating, dominating, obliging, avoiding and compromising. The another of this inventory reported the range of Cronbach alpha from .72 to .77. The individual alpha coefficients for each style are .75(Avoiding), .72(compromising), .72(dominating), .77(integrating), and .72(obliging). This method of measuring organizational conflict has been proven both valid and reliable through its use in previous studies (Brewer et al., 2002; Rahim, 1983; Song et al., 2006).

Bem Sex role Orientation Inventory: The Indian adaptation of Bem's psychological sex-role orientation inventory (BSRI-A) by Rao, Gupta and Murthy (1982) was used. The inventory (BSRI-A) consists of 15 'Masculine' and 15 'Feminine' adjectives. Participants responded in terms of how well each attribute describes themselves on a 7-point Likert scale, ranging 1=Never or almost never true; 7=Always or almost always true. Mean self-rating on each scale were computed separately and used together as in index of androgyny, or as characterization of the person's gender role identification. The present study used the median split method to categorize participants as masculine, feminine, androgynous or undifferentiated. Bem reported split-half validity for masculine and feminine to be .45 and .55 respectively. The validity coefficients for 
averages ratings of peers are reported by the author as 0.36 (masculine) and 0.37 for feminine. Validity coefficients with self-ratings are reported to be 0.16 for masculine and 0.34 for feminine.

To categorize the subjects into four gender roles the following method has to be based: Androgynous: Those having high scores on both masculine and feminine.

Masculine: Those having high scores on masculine and low scores on feminine.

Feminine: Those having low scores on masculine and high scores on feminine.

Undifferentiated: Those having low scores on both masculine and feminine.

\section{RESULT AND DISCUSSION}

To analyze the research hypotheses, which looked at the differences between status, residential area and conflict management strategies, a Two-way ANOVA was used. This method of analysis allowed the researcher to look at the two categories of status, residential and the multiple conflict management strategies, and the differences that existed between the two variables. The results obtained are presented in the following table.

Table : Factorial analysis of variance of conflict management style with reference to Status and residential area

\begin{tabular}{|c|c|c|c|c|c|}
\hline $\begin{array}{l}\text { Conflict } \\
\text { management style }\end{array}$ & $\begin{array}{l}\text { Source of } \\
\text { variation }\end{array}$ & $\begin{array}{ll}\text { Sum } \\
\text { squares }\end{array}$ & Df & $\begin{array}{l}\text { Mean of } \\
\text { Square }\end{array}$ & $\mathbf{F}$ \\
\hline \multirow{5}{*}{$\begin{array}{l}\text { Integrating conflict } \\
\text { management style }\end{array}$} & $\mathrm{A}($ Status $)$ & 200.45 & 1 & 200.45 & $10.84 * *$ \\
\hline & B(Area) & 86.56 & 1 & 86.56 & $4.68^{*}$ \\
\hline & ABss & 290.07 & 1 & 290.7 & $15.69 * *$ \\
\hline & Wss & 3993.02 & 216 & 18.49 & - \\
\hline & Tss & 4570.10 & 219 & - & - \\
\hline \multirow{5}{*}{$\begin{array}{l}\text { Compromising } \\
\text { conflict } \\
\text { management style }\end{array}$} & A(Status) & 8.80 & 1 & 8.80 & 1 \\
\hline & B(Area) & 10.47 & 1 & 10.47 & 1.18 \\
\hline & ABss & 19.33 & 1 & 19.33 & 2.19 \\
\hline & Wss & 1900.78 & 216 & 8.80 & - \\
\hline & Tss & 1939.38 & 219 & - & - \\
\hline \multirow{4}{*}{$\begin{array}{l}\text { Dominating } \\
\text { conflict } \\
\text { management style }\end{array}$} & A(Status) & 90.37 & 1 & 90.37 & $8.01 * *$ \\
\hline & B(Area) & 90.38 & 1 & 90.38 & $8.01 * *$ \\
\hline & ABss & 92.59 & 1 & 92.59 & $8.20^{* *}$ \\
\hline & Wss & 2436.35 & 216 & 11.28 & - \\
\hline
\end{tabular}


Conflict Management Styles of Female Androgynous Supervisor and Subordinate

\begin{tabular}{|l|l|l|l|l|l|}
\hline & Tss & 2709.69 & 219 & - & - \\
\hline \multirow{2}{*}{$\begin{array}{l}\text { Obliging conflict } \\
\text { management style }\end{array}$} & A(Status) & 32.84 & 1 & 32.84 & 3.60 \\
\cline { 2 - 7 } & B(Area) & 1.03 & 1 & 1.03 & 0.11 \\
\cline { 2 - 7 } & ABss & 35.5 & 1 & 35.5 & $3.88^{*}$ \\
\cline { 2 - 7 } & Wss & 1975.43 & 216 & 9.14 & - \\
\cline { 2 - 7 } & Tss & 2044.8 & 219 & - & - \\
\hline \multirow{2}{*}{$\begin{array}{l}\text { Avoiding conflict } \\
\text { management style }\end{array}$} & A(Status) & 21.0 & 1 & 21.01 & 1.33 \\
\cline { 2 - 7 } & B(area) & 45.45 & 1 & 45.45 & 2.88 \\
\cline { 2 - 7 } & ABss & 67.35 & 1 & 67.35 & $4.26^{*}$ \\
\cline { 2 - 7 } & Wss & 3408.94 & 216 & 15.78 & - \\
\cline { 2 - 7 } & Tss & 3542.75 & 219 & - & - \\
\hline
\end{tabular}

In the table the descriptive statistics of all the variables is given.

ANOVA result reveal significant status main effects for integrating $(\mathrm{F}=10.84, \mathrm{p}<.01)$ and significant effect on dominating conflict management style $(\mathrm{F}=8.01, \mathrm{p}<.01)$, which denotes that the mean score of supervisor employees higher in integrating conflict management style $(M=28.01)$ and dominating conflict management style $(M=16.26)$, than integrating conflict management style of subordinates $(\mathrm{M}=26.10)$ and dominating conflict management style $(\mathrm{M}=15.52)$ result shows that integrating and dominating style more prefer by organizational supervisor employees. In the integrating style of conflict management it involves the high assertiveness and high cooperativeness, high concern for self as well as other party involved in conflict, that is why it is more used. Integrating conflict management style is used when both parties involved attempt to create a solution that is a win for both sides. From the research conducted by As per research conducted by Polychroniou (2006) it is revealed that the designation of a person do affect the integrating conflict style. According to Goodwin (2000) high designation employees use more integrating conflict management style than low designation employees.

Results further reveal that on affective residential area, significant main effect of integrating conflict management styles $(\mathrm{F}=4.68, \mathrm{p}<.05)$ and dominating conflict management style $(\mathrm{F}=8.01$, $\mathrm{p}<.01)$. Result shows integrating style more prefer by employees of rural area $(\mathrm{M}=27.69)$ than employees of urban area $(\mathrm{M}=26.44)$ and in dominating conflict management style, employees of rural area (14.98) use more dominating style than organizational employees who lives in urban area (16.26).

The research hypotheses asked about the possible relationship between status, residential area and preferred conflict management styles. In two-way ANOVA revealed significant status and residential effect on integrating conflict management style $(\mathrm{F}=15.69, \mathrm{p}<.01)$, dominating conflict management style $(\mathrm{F}=8.20, \mathrm{p}<.01)$, Obliging conflict management style $(\mathrm{F}=3.88, \mathrm{p}<.05)$ and avoiding conflict management style $(\mathrm{F}=4.26, \mathrm{p} .>05)$ which despite the fact that there was grater relationships seen in status and residential area, only one of the five conflict management 
strategies not determined a relationship between status, residential area and conflict management styles. For further interpretation of this interaction of designation and residential area Post hoc Tukey test was applied to find out the significance of differences among mean scores of all the four groups. Results are shows that, the highest amount of integrating conflict management style shows on supervisor employees of rural area (28.52) and subordinates employees who lives in urban area (25.36) use this style less than other groups, on dominating conflict management subordinates employees who lives in rural area (16.32) are more use this style. Subordinates employees who lives in urban area (14.85) use this style less than other groups. similarly on obliging conflict management style, subordinates who lives in rural area(22.10) prefer more this conflict management style, Subordinates employees who lives in urban area (20.07) use this style less than other groups. This findings support the results of Supervisors employees who lives in rural area (21.05) use this style less than other groups. The results of this study determined many significant relationships between the different variables and conflict management strategies. Although significant differences were not found for status and residential on compromising, avoiding and obliging conflict management style. There were interesting interaction effect found between designation and residential area on compromising, obliging and avoiding conflict management styles.

\section{CONCLUSION}

There was a significant differences between integrating, and dominating style in respect to designation, residential area and conflict management style. As expected, there were more significant differences between status and residential area interaction and conflict management than status and conflict management. Here there has been seen that the effect of status on the conflict management style is less significant than the effect of status and residential area on conflict management style.

\section{REFERENCES:}

1. Appelbaum.S.H.,(2003) A journey through the landscape of theories. The Emerald Research for Journal.

2. Bem, S. L. (1974). The measurement of psychological androgyny. Journal of Consulting and Clinical Psychology.

3. Brewer, N., Mitchell, P., \& Weber, N. (2002). Gender role, organizational status, and conflict management styles. The International Journal of Conflict Management.

4. Canary, D. J., Cunningham, E. M., \& Cody, M. J. (1988). Goal types, gender, and locus of control in managing interpersonal conflict. Communication Research 15.

5. Chusmir, L.H. and Mills, J. (1989), "Gender differences in conflict resolution styles of managers: At work and at home", Sex Roles, Vol. 20.

6. Conrad, C. (1991). Communication in conflict: Style-strategy relationships. Communication Monographs. 
7. Domagalski, T. A., \& Steelman, L. A. (2007). The impact of gender and organizational status on workplace anger expression. Management Quarterly 20.

8. Friedman, R. A., Tidd, S. T., Currall, S. C., \& Tsai, J. C. (2000). What goes around comes around: The impact of personal conflict style on work conflict and stress. The International Journal of Conflict Management 11.

9. Gayle, M. B. (1991). Sex equity in workplace conflict management. Journal of Applied communication Research 19.

10. Gross, M. A., \& Guerrero, L. K. (2000). Managing conflict appropriately and effectively: An aapplication of the competence model to Rahim "es organizational conflict styles. The International Journal of Conflict Management.

11. Holt, J.L. and DeVore, C.J. (2005), "Culture, gender, organizational role, and styles of conflict resolution: A meta-analysis", International Journal of Intercultural Relations, Vol. 29 No. 2 ,

12. Infante, D. A., \& Gorden, W. I. (1981). Similarities and differences in the communicator styles of superiors and subordinates: Relations to subordinate satisfaction. Communication Quarterly 30.

13. Knapp, M. L., \& Putnam, L. L. (1988). Measuring interpersonal conflict in organizations: Where do we go from here? Management Communication Quarterly.

14. Korabik, K., Baril, G. L., \& Watson, C. (1993). Managers' conflict management style and leadership effectiveness: The moderating effects of gender. Sex Roles, 29.

15. Lamude, K. G., Daniels, T. D., \& Graham, E. E. (1988). The paradoxical influence of sex on communication rules coorientation and communication satisfaction in superiorsubordinate relationships. Western Journal of Speech Communication 52.

16. Orbe, M. P., \& Warren, K. T. (2000). Different standpoints, different realities: Race, gender, and perceptions of intercultural conflict. Qualitative Research Reports in Communication 1.

17. Portello, J.Y. \& Long, B.C. (1994). Gender orientation, ethical and interpersonal conflicts and Conflict handling styles of female managers. Sex Roles.

18. Powell, L., \& Hickson, M. (2000). Power imbalance and anticipation of conflict resolution: Positive and negative attributes of perceptual recall. Communication Research Reports. 